\title{
Subclinical markers of human inflammatory bowel disease
}

\author{
HUIYING YANG MD PHD, JEROME I ROTTER MD
}

H YANG, JI ROTTER. Subclinical markers of human inflammatory bowel disease. Can J Gastroenterol 1995;9(3):161-167. Genetic studies can be greatly aided by the use of subclinical markers that are closer to the basic defect and thus likely to detect more individuals with the abnormal genotype. At least two approaches are generally used to characterize subclinical markers. One is the family study approach. The detection of subclinical abnormalities in unaffected relatives similar to those found in the probands can distinguish between an inherited predisposition and a secondary abnormality due to the disease process. The second approach is the combination of subclinical marker with genetic marker studies. Specific association of a subclinical marker with a genetic marker indicates genetic determination of the subclinical marker. The identification of a genetically determined subclinical marker can help to define a more homogeneous disease group for genetic studies. The most studied subclinical markers in inflammatory bowel disease (IBD) are antineutrophil cytoplasmic antibodies (ANCAs) for ulcerative colitis (UC) and intestinal permeability for Crohn's disease (CD). Even so, for these as well as several other promising subclinical markers, there is an obvious need for more twin, family and genetic marker studies. An elevated intestinal permeability in a proportion of unaffected relatives of CD patients has been observed in the majority of family studies. ANCAs, a highly specific marker for UC, have been found with a significantly increased prevalence in unaffected relatives of UC patients compared with spouses of the patients. Moreover, the distribution of the ANCAs is familial rather than random, suggesting heterogeneity within UC. In combination with genetic marker studies (human leukocyte antigen [HLA] class II genes), the authors observed a differential association: ANCA-positive UC was associated with DR2, while ANCA-negative UC associated with DR4. These data lead to the conclusion that the heterogeneity indicated by ANCA is genetically determined and that this genetic heterogeneity should be taken into consideration in future genetic, clinical and pathophysiological studies. In the aggregate, these data indicate that the subclinical marker approach is a powerful means for demonstrating genetic and etiological heterogeneity, and can be an important tool to define the etiology and natural history of the various diseases that make up IBD. (Pour résumé, voir page 162)

Key Words: Antineutrophil cytoplasmic antibodies, Crohn's disease, Inflammatory bowel disease, Subclinical markers, Ulcerative colitis

Division of Medical Genetics and the Inflammatory Bowel Disease Center, Departments of Medicine and Pediatrics, Cedars-Sinai Medical Center, Los Angeles, California, USA

Correspondence: Dr H Yang, Division of Medical Genetics and the Inflammatory Bowel Disease Center, Departments of Medicine and Pediatrics, Cedars-Sinai Medical Center, 8700 West Beverly Boulevard, Los Angeles, CA 90048, USA. Telephone (310) 855-6451, Fax (310) 659-0491

This paper was presented at the Basic Research and Clinical Implications in IBD meeting, April 6 to 9, 1994, held in Victoria, British Columbia. This paper has also been published in Sutherland LR, et al, eds. Inflammatory Bowel Disease: Basic Research, Clinical Implications and Trends in Therapy. Boston, Dordrecht and London: Kluwer Academic Publishers, 1994 $\bigcup_{\text {techniques and clinical disease }}^{\text {EnetiC STUDies USING CliniCAL }}$ definition alone have their limits because clinically unaffected individuals with the variant genotype will not be recognized. Such studies can be greatly aided by the use of subclinical markers that are closer to the basic defect and thus likely to detect more individuals with the abnormal genotype (1). Subclinical markers are parameters used to detect the abnormal genotype in the absence of the full phenotype, eg, abnormal glucose tolerance and islet cell antibodies in diabetes or serum cholesterol in coronary artery disease. These markers represent abnormalities having a direct role in the pathogenesis of the disease. They are useful in genetic studies because in many disorders not all individuals with the mutant genotype may manifest the disorder (reduced penetrance), the variability of the phenotype may be so great that the clinical features are too mild to be readily apparent (variable expressivity) or there may be a delayed age at disease onset such that the younger genetically predisposed individuals would be clinically normal (1). Thus, subclinical markers maximize the number of affected individuals that can be detected.

In addition, the detection of subclinical abnormalities in unaffected family members similar to those found in the probands can distinguish between a primary defect indicating the presence of disease pathophysiology, and a secondary abnormality due to the disease process. Therefore finding such abnormalities in clinically unaffected family members helps establish an etiological role for a certain abnormality in 


\section{Marqueurs subcliniques de la maladie inflammatoire de l'intestin}

RÉSUMÉ : Dans des études de génétique, il peut être très utile de recourir à des marqueurs subcliniques, plus intimement liés aux anomalies de base et ainsi plus susceptibles d'identifier les sujets porteurs du génotype anormal. Au moins deux approches sont habituellement utilisées pour caractériser les marqueurs subcliniques. L'une est l'approche familiale. Le dépistage chez des proches non affectés d'anomalies subcliniques semblables à celles que l'on observe chez le probant peut permettre de distinguer entre prédisposition héréditaire et anomalie secondaire attribuable à un processus pathologique. La deuxième approche est l'association d'un marqueur subclinique et d'épreuves sur les marqueurs génétiques. L'association spécifique d'un marqueur subclinique avec un marqueur génétique indique une détermination génétique du marqueur subclinique. L'identification d'un marqueur subclinique à détermination génétique peut aider à définir un groupe de maladies plus homogène en vue des études génétiques. Les marqueurs subcliniques les plus étudiés dans la maladie inflammatoire de l'intestin sont les anticorps antineutrophiles cytoplasmiques (AANC) pour la colite ulcéreuse (CU) et la perméabilité intestinale dans la maladie de Crohn (MC). À ce chapitre et au sujet de nombreux autres marqueurs subcliniques au potentiel prometteur, il faudrait idéalement procéder à davantage d'études sur les marqueurs gémellaires, familiaux et génétiques. Une perméabilité intestinale accrue, dans une proportion de proches parents non affectés de patients atteints de MC, a été observée dans la majorité des études familiales. Les AANC, marqueurs très spécifiques de la CU, ont été notés avec une prévalence significativement accrue chez des proches non affectés de patients atteints de CU, en comparaison avec les conjoints de ces patients. De plus, la distribution des AANC est familiale plutôt que liée au hasard, ce qui suggère une certaine hétérogénéité dans la CU. En lien avec les épreuves sur les marqueurs génétiques (gène de l'antigène leucocytaire humain de classe II [HLA]), les auteurs ont observé une association différentielle : la CU positive à l'égard de l'AANC serait associée à DR2, alors que la CU négative à l'égard de l'AANC serait associée à DR4. Ces données permettent de conclure que l'hétérogénéité indiquée par la présence d'AANC est déterminée génétiquement et que cette hétérogénéité génétique devrait être prise en ligne de compte lors des épreuves génétiques cliniques et physiopathologiques. Dans l'agrégat, ces données indiquent que l'approche par marqueur subclinique est un moyen puissant de démontrer l'hétérogénéité génétique et étiologique et peut se révéler être un important outil pour définir l'étiologie et l'histoire naturelle de diverses maladies en jeu dans les MII.

TABLE 1

Subclinical marker studies in inflammatory bowel disease

\begin{tabular}{|c|c|c|}
\hline Marker & Observation & Reference/year \\
\hline $\begin{array}{l}\uparrow \text { Antibody to colonic epithelial } \\
\text { cells }\end{array}$ & $\begin{array}{l}\text { UC and } C D \text { patients' } \\
\text { relatives }\end{array}$ & Fiocchi et al (2)/1989 \\
\hline $\begin{array}{l}\uparrow \text { Antibody to crude colonic and } \\
\text { Escherichia coli }\end{array}$ & $\begin{array}{l}\text { UC patient's female } \\
\text { relative }\end{array}$ & Lagercrantz et al (3)/1971 \\
\hline$\downarrow$ Mucin species IV & UC patient's twin & Tysk et al (4)/1991 \\
\hline$\uparrow$ Mucosal cellular lgG 1 & UC patient's twin & Helgeland et al (5)/1992 \\
\hline$\uparrow$ IgA titres against gliadin & UC patient's twin & Lindberg et al (6)/1992 \\
\hline $\begin{array}{l}\uparrow \text { Antineutrophil cytoplasmic } \\
\text { antibodies }\end{array}$ & UC patient's relative & Shanahan et al (7)/1992 \\
\hline$\uparrow$ Lymphocytotoxic antibody & CD patient's relative & Korsmeyer et al (8)/1975 \\
\hline$\uparrow$ Complement dysfunction & CD patient's relative & Elmgreen et al (9)/1985 \\
\hline$\uparrow$ Intestinal permeability & CD patient's relative & Hollander et al (10)/1986 \\
\hline $\begin{array}{l}\uparrow \text { Obligate anaerobic fecal flora } \\
\text { (Gram-positive coccoid rods, } \\
\text { Gram-negative rods) }\end{array}$ & CD patient's children & $\begin{array}{l}\text { Van de Merwe et al (1 1 )/ } \\
1988\end{array}$ \\
\hline
\end{tabular}

CD Crohn's disease; Ig Immunoglobulin; UC Ulcerative colitis a disease. Such an abnormality may either indicate the genetic abnormality predisposing to a disease or identify those in whom an earlier, subclinical phase of the disease process is occurring that may eventuate in clinical disease. Although several abnormalities have been described in inflammatory bowel disease (IBD), only a few have yet been extended beyond the patients to include family members (Table 1) (2-11).

The important characteristics of a subclinical marker for genetic studies include high specificity, constancy, and familiality. Antineutrophil cytoplasmic antibodies (ANCAs) have all of these characteristics.

\section{ANCAs}

Specificity: A distinct subset of ANCAs was recently discovered to be highly specific for ulcerative colitis (UC) by Saxon and co-workers (12). Approximately $70 \%$ of UC patients are ANCA-positive compared with other forms of colitis, which include Crohn's disease (CD) (as low as 6\%) (12-16). ANCA is rare in normal controls. All available ANCA studies in IBD and related diseases are summarized in Table 2 (7,12-23). Although there are differences in the frequency of ANCAs between studies from different countries, the prevalence of ANCAs consistently is significantly increased in UC patients compared with those with CD. ANCAs observed in UC patients have higher titres, with a perinuclear immunofluorescence binding pattern (pANCA), whereas they have lower titres, with cytoplasmic pattern (cANCA), in CD sufferers (12,14). A high specificity indicates that this marker is disease specific, and therefore more likely to be involved in the pathogenesis of the disease.

The prevalence of ANCAs is also significantly increased in patients with primary sclerosing cholangitis (PSC), which is clinically associated with UC. The shared increase in ANCAs in both UC and PSC may indicate that there is a common antigenic target for immunemediated attack on both colonic and binary epithelial cells. Further support of this concept is that a 40,000 molecular weight colonic epithelial protein 
has been identified with a unique epitope(s) that is shared by the skin and biliary tract epithelial cells (24).

Constancy: The presence of ANCAs appears to be independent of disease activity, duration of illness, localization, extent of disease, previous bowel operations or medical treatment $(12,15,20$, 21). ANCAs are also found in UC patients who are five or more years postcolectomy. ANCAs not only are persistent, but also may have clinical implications. For example, ANCAs have been reported to occur with increased frequency in those postcolectomy UC patients who experience the subsequent inflammation termed 'pouchitis', compared with those who did not develop pouchitis $(25,26)$. The presence of ANCA is not only an indicator of the risk for UC, but also an indicator of the high risk for complications of postcolectomy in UC patients. The presence of ANCAs is thus not simply an epiphenomenon related to active colonic inflammation, but may reflect a fundamental disturbance of immune regulation.

Familiality: Because the relatives of IBD patients have a higher risk than the general population of developing IBD, the prevalence of a subclinical marker is expected to be increased among relatives of IBD patients compared with the general population, an observation termed 'increased familial aggregation' or simply 'familiality'. Family or twin studies can be used to demonstrate familiality.

In a family study of ANCAs, the authors have demonstrated that the clinically healthy relatives of UC patients have an increased frequency of positive ANCAs (16\%) compared with environmental controls (3\%) (7). They also observed that second degree relatives who are not sharing the same household with the probands have an increased prevalence of ANCAs and that the household controls are not at an increased risk for ANCA (7). These important epidemiological observations suggest that the familial aggregation of ANCAs is due to the shared genetic factors among the family members, and not due to shared environmental factors.

TABLE 2

Antineutrophil cytoplasmic antibodies (ANCAs) in ulcerative colitis and other associated diseases

\begin{tabular}{lcccccl}
\hline & \multicolumn{9}{c}{$\%$ of pANCA } \\
Location & UC & CD & PSC & Control & Other & Reference/year \\
\hline USA & 68 & 12 & - & 0 & - & Saxon et al $(12) / 1990$ \\
USA, Canada & 61 & 6 & - & 0 & $<2$ & Duerr et al $(14) / 1991$ \\
USA & 68 & - & 65 & - & 0 & Duerr et al $(17) / 1991$ \\
USA, Canada & 68 & - & - & 3 & - & Shanahan et al $(7) / 1992$ \\
Norway & 27 & 0 & 63 & 0 & - & Zauli et al $(18) 1992$ \\
Germany & 83 & 25 & $40^{*}$ & - & - & Seibold et al $(13) / 1992$ \\
France & 50 & - & - & 0 & - & Reumaux et al $(19) / 1992$ \\
Sweden & 50 & 8 & 50 & - & - & Peen et al $(16) / 1993$ \\
Netherlands & 79 & 13 & - & 9 & - & Oudkerk-Pool et al $(20) / 1993$ \\
Greece & 30 & - & - & - & - & Dalekos et al $(21) / 1993$ \\
UK & - & - & 80 & $0^{\dagger}$ & - & Lo et al $(22) / 1993$ \\
UK & 54 & 10 & - & 0 & - & Cambridge et al $(15) / 1993$ \\
Hong Kong & 32 & - & - & 0 & - & Sung et al $(23) / 1993$ \\
\hline
\end{tabular}

*88 primary sclerosing cholangitis (PSC) + ulcerative colitis (UC); ${ }^{\dagger}$ All in children; CD Crohn's disease, PANCA ANCAs with a perinuclear immunofluorescence binding pattern

A second important finding in this published family study was the significant difference in the frequency of ANCAs in the relatives of probands whose sera were ANCA-positive compared with the relatives of probands whose sera were ANCA-negative (7). This concordant familial distribution indicates heterogeneity within UC.

Genetic marker studies with ANCAs: Although epidemiological observations have suggested the important genetic contributions to the development of ANCAs, genetic marker studies provide definitive evidence for the genetic determination of ANCAs in IBD.

HLA class II genes: It has been shown that UC is associated with the human leukocyte antigen (HLA) DR2 allele $(27,28)$. When UC patients were subdivided into ANCA-positive and -negative groups, ANCA-positive UC patients had a significantly increased frequency of DR2 compared with ANCA-negative controls ( $44 \%$ versus $22 \%)$. In contrast, the frequency of DR2 in ANCA-negative UC cases (21\%) was virtually identical to that in controls (22\%) (29). In addition, the ANCA-negative UC patients had an increase in the DR4 allele compared with ANCA-positive UC patients. Therefore, the heterogeneity within UC indicated by ANCAs has a genetic basis. This genetic marker study further supports the
TABLE 3

Characteristics of ulcerative colitis (UC)-associated antineutrophil cytoplasmic antibodies (ANCAs)

A subset of ANCAs associated with UC (50 to $86 \%$ UC)

Specific for UC compared with other forms of colitis

Independent of clinical features

Present in healthy relatives of UC cases

Familial distribution in the presence of ANCAs (ANCA-positive and -negative UC families)

Differential association of human leukocyte antigen class II alleles as a function of ANCA status

epidemiologic observations: genetic susceptibility is an essential factor for the development of ANCAs.

Presently, by the combination of family and gene marker studies, ANCAs are the most established subclinical marker for any form of IBD (Table 3).

\section{PERMEABILITY STUDIES}

Since the initial family study of permeability in $\mathrm{CD}(10)$ there have been several additional studies (Table 4). On first inspection, the results appear somewhat inconsistent. A number of related factors may affect the results of an intestinal permeability study. These may include the type of probes, the 
TABLE 4

Permeability studies in relatives of patients with Crohn's disease

\begin{tabular}{|c|c|c|c|c|c|c|}
\hline \multirow[b]{3}{*}{ Reference/year } & \multicolumn{6}{|c|}{ Probes } \\
\hline & \multicolumn{2}{|c|}{ Polyethylene glycol } & \multicolumn{2}{|c|}{ Lactulose } & \multicolumn{2}{|c|}{${ }^{51} \mathrm{Cr}-\mathrm{EDTA}$} \\
\hline & Mean & $10 \%{ }^{*}$ & Mean & $10 \% *$ & Mean & $10 \% *$ \\
\hline Hollander et al (10)/1986 & ++ & ++ & & & & \\
\hline Katz et al (30)/1989 & & & - & ++ & & \\
\hline Ainsworth et al (31)/1989 & & & & & - & - \\
\hline Ruttenberg et al (32)/1992 & - & ++ & & & & \\
\hline Teahon et al (33)/1992 & & & ( & ++ & & ++ \\
\hline Valpiani et al (34)/1992 & & & - & ++ & & \\
\hline Pironi et al (35)/1992 ${ }^{\dagger}$ & & & ++ & ++ & & \\
\hline May et al (36)/1993 & & & ( & ++ & & \\
\hline
\end{tabular}

${ }^{*}$ At least $10 \%$ of relatives have a significantly increased permeability compared with controls (estimated in reference 37); 'Used prior acetylsalicylic acid to augment permeability test; +Significant increase compared with controls; (Increase in relatives, but not statistically significant; -No difference between relatives and controls

method of administration of the probe (eg, fasting/nonfasting, with meals/ without meals [38]), day urine collection/overnight urine collection, length of urine collection and use of acetylsalicylic acid (ASA) as a challenge (39). It is important for this area of investigation to identify a sensitive and reproducible protocol for permeability testing that reliably separates $C D$ patients (or CD subgroup) from controls. In addition, it has been proposed that some of the statistical methods used to illustrate the increased permeability in the relatives of patients with $\mathrm{CD}$ may give misleading results (37). Rather than comparing the means of permeability between the two groups - relatives and controls - one can examine the proportion of the asymptomatic relatives of patients with $\mathrm{CD}$ who have permeability values above the upper limits of the range of values in normal controls. The logic of this latter approach is that presumably only a proportion of $\mathrm{CD}$ relatives are genetically susceptible. This was recently done (36), and the investigators found that approximately $10 \%$ of these relatives had a significant increase in intestinal permeability. When re-examining the published studies by this same approach (ie, defining an increased level as greater than two standard deviations above the mean in controls), Hollander (37) found that the majority of such studies showed a significant increase in intestinal permeability in a fraction of the asymptomatic relatives of patients with CD (Table 4). The possibility of abnormal permeability in relatives remains an attractive hypothesis either as a genetic abnormality or as a marker of early inflammation (40), but this field needs additional studies and methodological standardization. Possibly the most interesting approach was presented by Pironi et al (35). In their study, both healthy relatives of $\mathrm{CD}$ patients and healthy controls were given the lactulose/mannitol (L/M) test before and after ASA administration. These investigators concluded that the relatives of $\mathrm{CD}$ patients were more sensitive to nonsteroidal antiinflammatory drugs than healthy controls, ie, the mean percentage increase of above baseline L/M values observed after ASA was greater in relatives than in controls. Thus, these results suggest that an enhanced small bowel mucosal sensitivity to factors increasing permeability can play a primary role in the pathogenesis of the disease. However, more subjects need to be studied to confirm their findings.

\section{OTHER POTENTIAL SUBCLINICAL MARKERS}

Both UC and CD - antibodies to colonic epithelial cells: Antibodies to colonic epithelial cells have been reported in both CD and UC patients (28). One study assessed the immune reactivity to gut epithelial cell antigens in healthy members of families of patients with IBD (2). Specific lysis against epithelial cell-associated component antigens (colon-derived) among patients with IBD and among their unaffected first degree family members was significantly higher than in control groups $(70 \%$ in IBD patients, $56 \%$ in relatives and $8 \%$ in controls). The possibility has been raised that these antibodies might reflect environmental, in addition to genetic, factors because of their high prevalence in nonrelated family members (41).

In UC - antibodies to crude colonic and Escherichia coli: Elevated titres of antibodies to crude colonic and E coli $0: 14$ antigens have been found not only in patients with UC but also in their healthy female relatives (3).

In UC - mucosal production of immunoglobulin $G$ subclasses: The importance of immunoglobulin (Ig) Gmediated immunopathological processes in IBD has been suggested by the increased IgG cell fraction (42) and the elevated secretion of $\operatorname{IgG}(43)$ in the affected tissues. It has been also shown that there is a significant difference between UC and CD in terms of IgG subclass production in the mucosal lesion: the proportion of $\mathrm{IgG}_{1}$ immunocytes has been found to be higher in UC than in $\mathrm{CD}$, while the reverse was true for the $\mathrm{IgG}_{2}$ cell fraction (44). A recent twin study revealed an interesting result: there was no difference in the cellular IgG subclass pattern between healthy and affected UC twins (ie, where the index twin had UC), and the proportion of $\mathrm{IgG}_{1}$ in these healthy and diseased twins was significantly correlated (5). In UC, the aberrant mucosal production of $\mathrm{IgG}_{1}$ and $\mathrm{IgG}_{2}$ did not depend on active disease and the raised $\mathrm{IgG}_{1}$ proportion appeared to be disease-specific (5). These findings suggest that genetic mechanisms appear to be involved in the regulation of the $\mathrm{IgG}$ subclass response.

In UC - antibodies to gliadin: In a twin study examining antibody (IgG, IgA and IgM) to baker's yeast, yeast mannan, gliadin, ovalbumin and betalactoglobulin, high IgA titres against gliadin were found in healthy and diseased UC monozygotic twins (6). This may indicate a subclinical and/or genetically determined gluten intolerance. 
In UC - mucin abnormalities: The gastrointestinal tract is lined with a mucous layer that forms a barrier against exotoxins and microorganisms. One etiological hypothesis is that inborn abnormalities in colonic mucin species may be related to the pathogenesis of UC (45-47).

The content of the chromatographically defined component of colonic mucin designated human colonic mucin species IV has been reported to be reduced in both patients with UC and their apparently healthy twins (4). Composition of the mucins in CD patients and their unaffected twins was not significantly different from controls. These observations suggest that altered profiles of mucin glycoprotein may be present before the onset of UC and therefore may be genetically defined.

In CD - lymphocytotoxic antibodies: Autoantibodies to lymphocyte surface membrane antigens (lymphocytotoxic antibodies) have been found in increased frequency in patients with $\mathrm{CD}$ and their relatives, but have also been found in increased frequency in their spouses (8). In addition, these antibodies are not specific to IBD and have been found in a variety of other diseases, such as systemic lupus erythematosus, rheumatoid arthritis and malaria, all involving active immune responses (48).

In CD - complement dysfunction: In a study of CD patients and their clinically unaffected first degree relatives, $38 \%$ of

\section{REFERENCES}

1. King RA, Rotter JI, Motulsky AG, eds. The Genetic Basis of Common

Diseases. New York: Oxford University Press, 1992.

2. Fiocchi C, Roche JK, Michener WM. High prevalence of antibodies to intestinal epithelial antigens in patients with inflammatory bowel disease and their relatives. Ann Intern Med 1989;110:786-94.

3. Lagercrantz R, Perlmann P, Hammerstrom S. Immunological studies in ulcerative colitis. V. Family studies. Gastroenterology 1971;60:381-9.

4. Tysk C, Riedesel H, Lindberg E, Panzini B, Podolsky D, Jarnerot G. Colonic glycoproteins in monozygotic twins with inflammatory bowel disease. Gastroenterology 1991;100:419-23. cases and $18 \%$ of relatives showed subnormal generation of chemotactic activity and decreased use of $\mathrm{C} 3$ by the alternative complement pathway (9). All of the relatives with $\mathrm{C} 3$ abnormalities were confined to families of probands with similar abnormalities, suggesting that: the abnormalities are not simply secondary to $\mathrm{CD}$; the abnormalities are familial; and because they occurred only in some families and not others, these abnormalities predispose in only a subset of CD.

In CD - obligate anaerobic fecal flora: The obligate aerobic fecal flora of $\mathrm{CD}$ patients has been shown to be different from that of healthy controls (CD flora has more Gram-positive coccoid rods and Gram-negative rods than the flora of healthy subjects) (49-51). To investigate whether the abnormal fecal flora is a genetically determined condition that predisposes an individual to the development of CD (52), a family study was conducted (11). The investigators observed that nine of 26 clinically healthy children of $\mathrm{CD}$ patients $(35 \%)$ had abnormal aerobic flora, similar to the frequency in $\mathrm{CD}$ patients. In five to seven years of follow-up, three of the nine children with abnormal flora developed symptoms suggestive of $\mathrm{CD}$ and one was diagnosed with $\mathrm{CD}$, while none of the 17 children with a normal flora showed symptoms consistent with CD. Thus, the abnormal flora may be indigenous to subjects predisposed to $\mathrm{CD}$. It appears this may be limited to the

5. Helgeland L, Tysk C, Jarnerot G, et al. $\operatorname{IgG}$ subclass distribution in serum and rectal mucosa of monozygotic twins with or without inflammatory bowel disease. Gut 1992;33:1358-64.

6. Lindberg E, Magnusson K-E, Tysk C, Jarnerot G. Antibody (IgG, IgA, and IgM) to baker's yeast (Saccharomyces cerevisiae), yeast mannan, gliadin, ovalbumin and betalactoglobulin in monozygotic twins with inflammatory bowel disease. Gut 1992;33:909-13.

7. Shanahan F, Duerr RH, Rotter JI, et al. Neutrophil autoantibodies in ulcerative colitis: familial aggregation and genetic heterogeneity.

Gastroenterology 1992;103:456-61.

8. Korsmeyer SJ, Williams RC Jr, Wilson ID, Strickland RG. Lymphocytotoxic antibody in inflammatory bowel disease early onset patient population because the siblings and parents of the $\mathrm{CD}$ patients did not show abnormal flora. If the basic observation is confirmed, then it needs to be determined whether the relationship between the abnormal fecal flora and $\mathrm{CD}$ is direct (products or cell wall fragments consisting of peptidoglycan and/or lipopolysaccharides could initiate the inflammatory reaction) (53) or indirect (the abnormal flora were less resistant to colonization of the bowel by pathogenic bacteria).

\section{CONCLUSIONS}

IBD is a genetically heterogeneous group of disorders. We are still at the beginning stage of using subclinical markers to understand the genetics of IBD. In future genetic studies, these subclinical markers (currently, at the minimum ANCAs) should be taken into consideration for classification of the patients and families to obtain an etiologically homogeneous groups. Natural history studies are needed to understand the role of ANCAs and eventually other subclinical markers in the development of clinical IBD.

ACKNOWLEDGEMENTS: Supported in part by grants from the Crohn's and Colitis Foundation of America, National Institutes of Health Program Project grant DK46763, the Stuart Foundations, and the Cedars-Sinai Board of Governors' Chair in Medical Genetics.

- A family study. N Engl J Med 1975;293:1117-20.

9. Elmgreen J, Both H, Binder V. Familial occurrence of complement dysfunction in Crohn's disease: correlation with intestinal symptoms and hypercatabolism of complement. Gut 1985;26:151-7.

10. Hollander D, Vadheim CM, Brettholtz E, Petersen GM, Delahunty T, Rotter JI. Increased intestinal permeability in Crohn's patients and their relatives: an etiological factor? Ann Intern Med 1986;105;883-95.

11. Van de Merwe JP, Schroder AM, Wensinck F, Hazenberg MP. The obligate anaerobic faecal flora of patients with Crohn's disease and their first-degree relatives. Scand J Gastroenterol 1988;23:1125-31.

12. Saxon A, Shanahan F, Landers C, Ganz T, Targan S. A subset of 
antineutrophil anticytoplasmic antibodies is associated with inflammatory bowel disease. J Allergy Clin Immunol 1990;86:202-10.

13. Seibold F, Weber P, Klein R, Berg PA, Wiedmann KH. Clinical significance of antibodies against neutrophils in patients with inflammatory bowel disease and primary sclerosing cholangitis. Gut 1992;33:657-62.

14. Duerr RH, Targan SR, Landers CJ, Sutherland LR, Shanahan F. Anti-neutrophil cytoplasmic antibodies in ulcerative colitis. Comparison with other colitides/diarrheal illnesses. Gastroenterology 1991;100:1590-6.

15. Cambridge G, Rampton DS, Stevens TRJ, McCarthy DA, Kamm M, Leaker B. Anti-neutrophil antibodies in inflammatory bowel disease: prevalence and diagnostic role. Gut 1992;33:668-74.

16. Peen E, Almer S, Bodemar G, et al. Anti-lactoferrin antibodies and other types of ANCA in ulcerative colitis, primary sclerosing cholangitis, and Crohn's disease. Gut 1993;34:56-62.

17. Duerr RH, Targan SR, Landers CJ, et al. Neutrophil cytoplasmic antibodies: a link between primary sclerosing cholangitis and ulcerative colitis. Gastroenterology 1991;100:1385-91

18. Zauli D, Baffoni L Cassani F, et al. Antineutrophil cytoplasmic antibodies in primary sclerosing cholangitis, ulcerative colitis, and autoimmune diseases. Gastroenterology 1992;102:1088-95.

19. Reumaux D, Delecourt L, Colombel JF, Nobl LH, Duthilleul P, Corlot A. Anti-neutrophil cytoplasmic autoantibodies in relatives of patients with ulcerative colitis. Gastroenterology 1992;103:1706.

20. Oudkerk-Pool M, Ellerbroek PM, Ridwan BU, et al. Serum antineutrophil cytoplasmic autoantibodies in inflammatory bowel disease are mainly associated with ulcerative colitis. A correlation study between perinuclear antineutrophil cytoplasmic autoantibodies and clinical parameters, medical, and surgical treatment. Gut 1993;34:46-50.

21. Dalekos GN, Manoussakis MN, Goussia AC, Tsianos EV, Moutsopoulos HM. Soluble interleukin-2 receptors, antineutrophil cytoplasmic antibodies, and other autoantibodies in patients with ulcerative colitis. Gut 1993;34:658-64.

22. Lo SK, Chapman RWG, Cheeseman P, et al. Antineutrophil antibody: a test for autoimmune primary sclerosing cholangitis in childhood? Gut 1993;34:199-202.

23. Sung JY, Chan KL, Hsu R, Liew CT,
Lawton JW. Ulcerative colitis and antineutrophil cytoplasmic antibodies in Hong Kong Chinese. Am J Gastroenterol 1993;88:864-9.

24. Das KM, Vecchi M, Sakamaki S. A shared and unique epitope(s) on human colon, skin, and biliary epithelium detected by a monoclonal antibody. Gastroenterology 1990;98:464-9.

25. Sandborn WJ, Landers CJ, Tremaine WJ, Targan SR. The presence of antineutrophil cytoplasmic antibody correlates with pouchitis after ileal pouch-anal anastomosis for ulcerative colitis. Gastroenterology 1993;104:A774.

26. Vecchi M, Giochetti P, Bianchi MB, et al. P-ANCA reactivity in ulcerative colitis patients with and without pouchitis after proctocolectomy. Gastroenterology 1993;104:A796.

27. Toyoda H, Wang S-J, Yang H, et al. Distinct association of HLA class II genes with inflammatory bowel disease. Gastroenterology 1993;104:741-8.

28. Yang H, Rotter JI. The genetics of inflammatory bowel disease: genetic predispositions, disease markers, and genetic heterogeneity. In: Targan SR, Shanahan F, eds. Inflammatory Bowel Disease: From Bench to Bedside. Baltimore: Williams and Wilkins, 1994:32-64.

29. Yang H, Rotter Ji, Toyoda H, et al. Ulcerative colitis: A genetic heterogeneous group defined with genetic (DR2) and subclinical markers (antineutrophil cytoplasmic antibodies). J Clin Invest 1993;92:1080-4.

30. Katz KD, Hollander D, Vadheim CM, et al. Intestinal permeability in Crohn's disease patients and their healthy relatives. Gastroenterology 1989;97:927-31.

31. Ainsworth M, Eriksen J, Rasmussen JW, Schaffalitzky de Muckadell OB. Intestinal permeability of ${ }^{51} \mathrm{Cr}$-labelled ethylenediaminetetraacetic acid in patients with Crohn's disease and their healthy relatives. Scand J Gastroenterol 1989;24:993-8.

32. Ruttenberg D, Young GO, Wright JP, Isaacs S. PEG-400 excretion in patients with Crohn's disease, their first-degree relatives, and healthy volunteers. Dig Dis Sci 1992;37:705-8.

33. Teahon K, Smethurst P, Levi AJ, Menzies IS, Bjarnason I. Intestinal permeability in patients with Crohn's disease and their first degree relatives. Gut 1992;33:320-3.

34. Valpiani D, Ornigotti L, Ricca Rosellini S, et al. Intestinal permeability in patients with Crohn's disease and in first grade relatives. Gastroenterology 1992;102:A708.
35. Pironi L, Miglioli M, Ruggeri E, et al. Effect of non-steroidal antiinflammatory drugs (NSAID) on intestinal permeability in first degree relatives of patients with Crohn's disease. Gastroenterology 1992;102:A679.

36. May GR, Sutherland LR, Meddings JB. Is small intestinal permeability really increased in relatives of patients with Crohn's disease? Gastroenterology 1993;104:1627-32.

37. Hollander D. Permeability in Crohn's disease: altered barrier functions in healthy relatives? Gastroenterology 1993;104:1848-51.

38. Bjarnason I, Smethurst P, Macpherson A, et al. Glucose and citrate reduce the permeability changes caused by indomethacin in humans. Gastroenterology 1992;102:1546-50.

39. Bjarnason I, Smethurst P, Levi AJ, Menzies IS, Peters TJ. The effect of polyacrylic acid polymers on small-intestinal function and permeability changes caused by indomethacin. Scand J Gastroenterol 1991;26:685-8

40. Hollander D. The intestinal permeability barrier. Scand J Gastroenterol 1992;27:721-6.

41. Seidan MV. Environmental or genetic effects in inflammatory bowel disease. Ann Intern Med 1989;111:445-6.

42. Baklien K, Brandtzaeg P. Comparative mapping of the local distribution of immunoglobulin-containing cells in ulcerative colitis and Crohn's disease of the colon. Clin Exp Immunol 1975;22:197-209.

43. Scott MG, Nahm MH, Macke K, Nash GS, Bertovich MJ, MacDermott RP. Spontaneous secretion of IgG subclasses by intestinal mononuclear cells: differences between ulcerative colitis, Crohn's disease, and controls. Clin Exp Immunol 1986;66:209-15.

44. Kett K, Rognum TO, Brandtzaeg P. Mucosal subclass distribution of immunoglobulin G-producing cells is different in ulcerative colitis and Crohn's disease of the colon. Gastroenterology 1987;93:919-24.

45. Cope GF, Heatley RV, Kelleher J, Axon ATR. In vitro mucus glycoprote in production by colonic tissue from patients with ulcerative colitis. Gut 1988;29:229-34.

46. Podolsky DK, Isselbacher KJ. Comparison of human colonic mucin. Selective alteration in inflammatory bowel disease. J Clin Invest 1983;72:142-53.

47. Podolsky DK, Isselbacher KJ. Glycoprotein composition of colonic mucosa. Specific alterations in ulcerative colitis. Gastroenterology 1984;87:991-8 
48. Elson CO. The immunology of inflammatory bowel disease. In: Kirsner JB, Shorter RG, eds. Inflammatory Bowel Disease, 3rd edn. Philadelphia: Lea and Febiger, 1988:97-164.

49. Wensinck F. Proceedings: The faecal flora of patients with Crohn's disease. Antonie Van Leeuwenhoek 1975;41:214-5.

50. Wensinck F, Custers-Van Lieshout
LMC, Poppelaars-Kustermans PAJ, Schroder AM. The faecal flora of patients with Crohn's disease. J Hygiene 1981;87:1-12.

51. Ruserer-Van Embden JGH, BothPatoir HC. Anaerobic Gramnegative faecal flora in patients with Crohn's disease and healthy subjects. Antonie Van Leeuwenhoek 1983;49:125-32.
52. Van de Merwe JP, Stegeman $\mathrm{JH}$, Hazenberg MP. The resident faecal flora is determine by genetic characteristics of the host. Implications for Crohn's disease? Antonie Van Leeuwenhoek 1983;49:119-24.

53. Sartor RB, Cromartie WJ, Powell DW, Schwab JH. Granulomatous enterocolitis induced in rats by purified bacterial cell wall fragments. Gastroenterology 1985;89:587-95. 


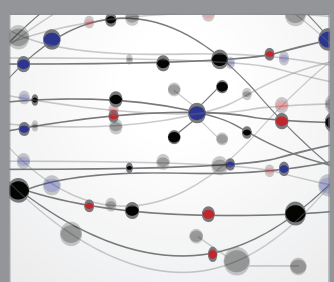

The Scientific World Journal
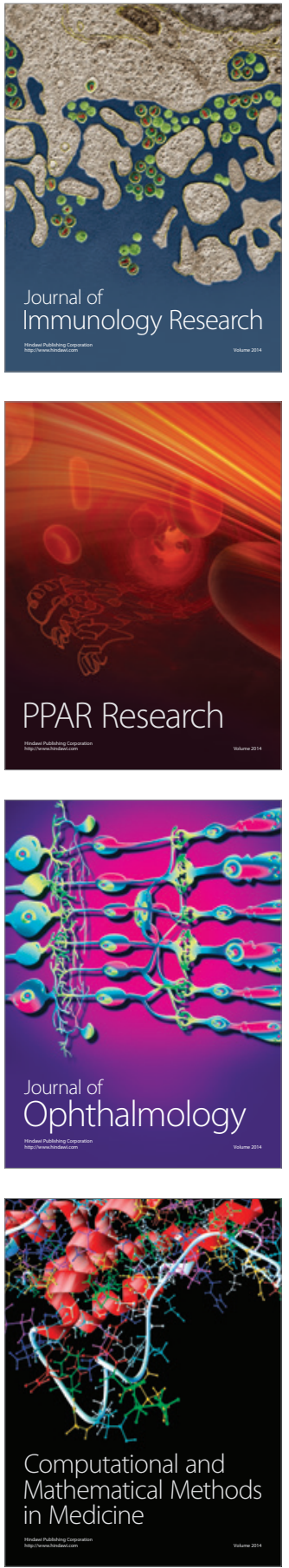

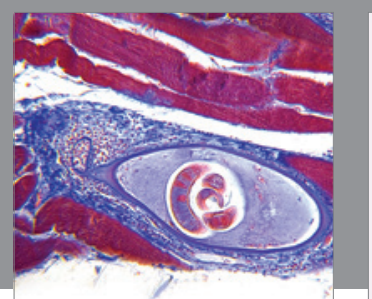

Gastroenterology Research and Practice

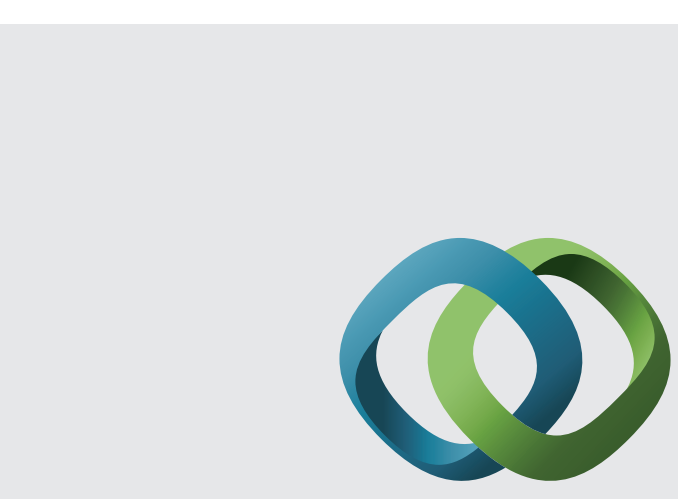

\section{Hindawi}

Submit your manuscripts at

http://www.hindawi.com
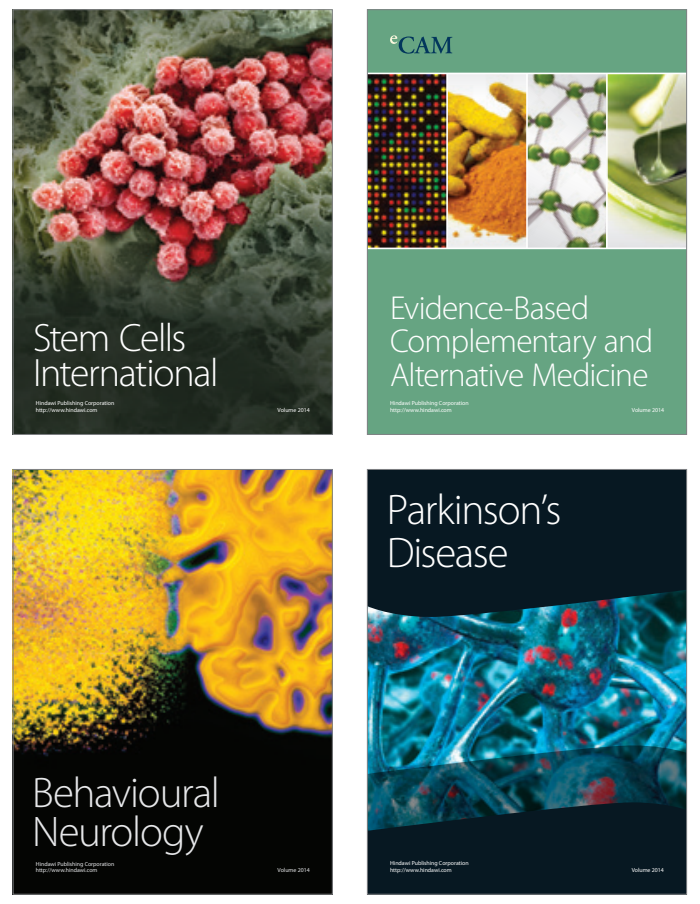
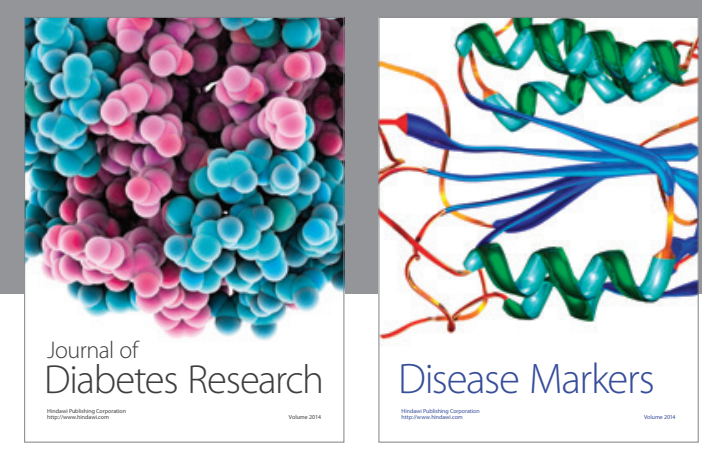

Disease Markers
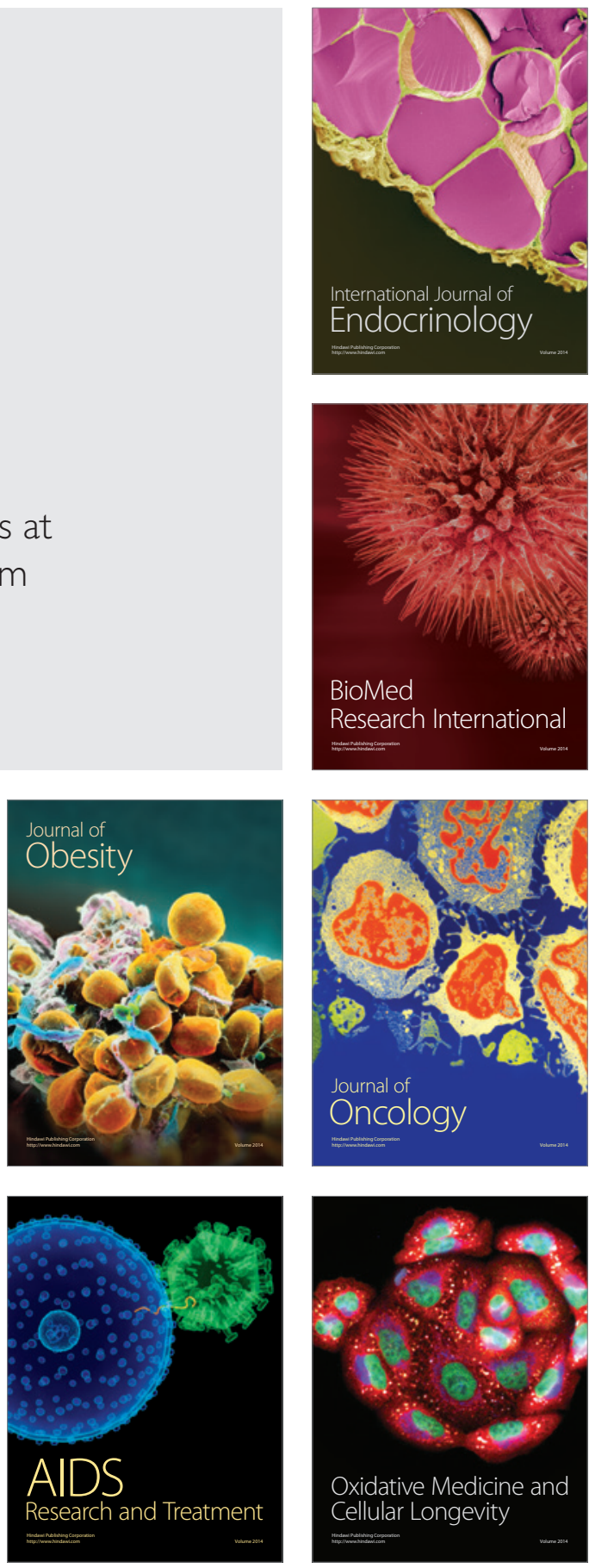